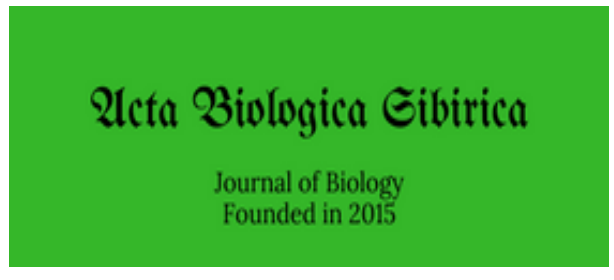

Altai State University

www.asu.ru

ISSN 2412-1908

Acta Biologica Sibirica, 2019, 5(1), 6-11

\title{
First records of long-legged flies (Diptera, Dolichopodidae) from Fars Province of Iran
}

\author{
S. Rezaei ${ }^{1}$, I.Ya. Grichanov², M. Fallahzadeh ${ }^{1}$ \\ ${ }^{1}$ Department of Entomology, Jahrom Branch, Islamic Azad University, Jahrom, Iran. \\ E-mails: rezaei.shohreh91@yahoo.com,mfalahm@yahoo.com \\ ${ }^{2}$ All-Russian Institute of Plant Protection, Podbelskogo 3, 196608, St.Petersburg-Pushkin, Russia. \\ E-mail: grichanov@mail.ru
}

This paper provides data on distribution of 9 long-legged fly species (Diptera, Brachycera, Dolichopodidae) belonging to 6 genera from Fars province, southern Iran. Four species, Asyndetus albifrons Loew, 1869, Asyndetus chaetifemoratus Parent, 1925, Medetera media Parent, 1925 and Sciapus adumbratus (Becker, 1902) are newly added to the Iranian insect fauna. In addition, available information for each species and comments on geographical distribution and taxonomy are also included.

Key words: Dolichopodidae; Iran; Fars; new records

\section{Introduction}

Iranian entomological fauna is receiving an increasing interest in the last few years, compensating for the long dated lack of knowledge. The family Dolichopodidae (Diptera, Brachycera) is not the exception, with a number of papers published in the last years. Most of these studies have been conducted in northern (e.g. Khaghaninia, Gharajedaghi, \& Grichanov, 2014; Kazerani, Khaghaninia, \& Grichanov, 2014; Kazerani, Khaghaninia, Talebi, Persson \& Pollet, 2017) or central parts (e.g. Ahmadi, Gheibi, Ostovan, Hesami, \& Grichanov, 2016; Ahmadi, Gheibi, Ostovan, Hesami, \& Grichanov, 2017) of Iran, and so far practically no studies have been conducted in southern parts of the country. The Fars province (coordinates $27^{\circ} 01^{\prime}-31^{\circ} 51^{\prime} \mathrm{N}, 50^{\circ} 27^{\prime}-55^{\circ} 45^{\prime} \mathrm{E}$ ) is located in southern Iran (Fig. 1). It is the fourth largest province of the country, covering an area of $122,400 \mathrm{~km}^{2}$. The climate in the province varies across counties. The north and northwest areas experience mild summers and moderately cold winters, whereas the weather is hot and dry in the south and southeast. The central region and the surrounding areas have hot dry summers and relatively rainy mild winters. Information on Dolichopodidae of the Fars Province has not been available before our investigation. The aim of current study was to increase our knowledge regarding Iranian long-legged flies, studying Dolichopodidae from southern Iran.

\section{Material and methods}

The specimens were collected by Malaise traps in four different localities of the Fars province (South Iran). Sampling localities are briefly described below and shown in Figures 1 and 2.

Loc. A): IRAN, Fars, Dalin, 5207'54.7"E, 3002'15.0"N.

Dalin is a small village in Hamaijan rural district, Sepidan County. Dalin is located in the west of Fars province, having a cold and mountainous climate with green and breezy summers and snowy winters. Diverse rivers favour the cultivation of, for example, apple (Malus pumila Miller), plum tree (Prunus spp.) and walnut (Juglans regia L.) orchards.

Loc. B): IRAN, Fars, Shiraz County, Jannat garden, 52²8'9.147"E, 29³6'52.373"N.

The climate has distinct seasons, and is overall classed as a hot semi-arid climate, though it is only a little short of a hot-summer Mediterranean climate. Shiraz contains a considerable number of gardens. Jannat garden has a large number of fruit trees and ornamental plants including walnut, pomegranate (Punica granatum L.), pine (Pinus ssp.) and cypress trees (Cupressus sempervirens L.). 


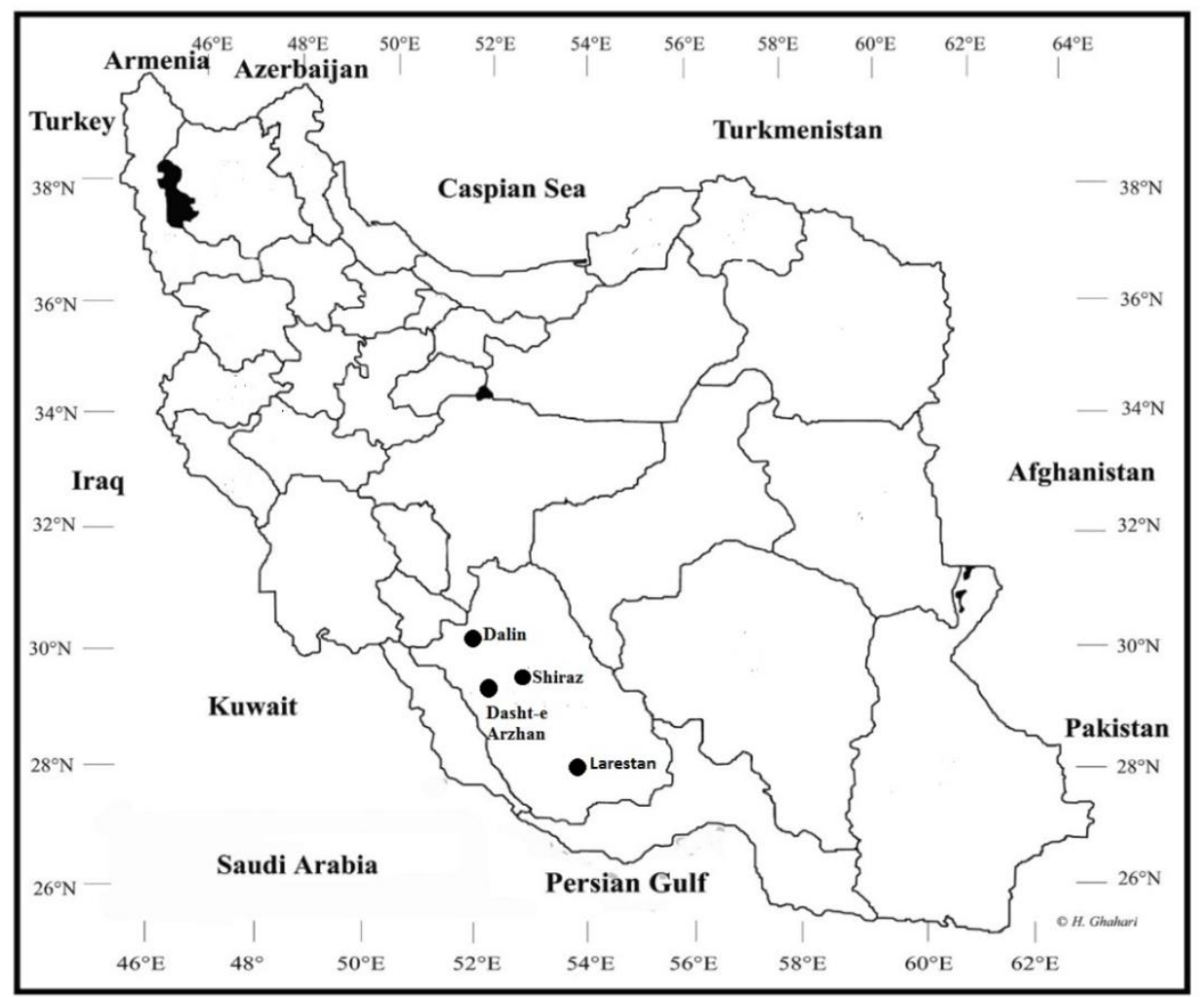

Fig. 1. Map of Iran and location of the sampling localities in Iran.
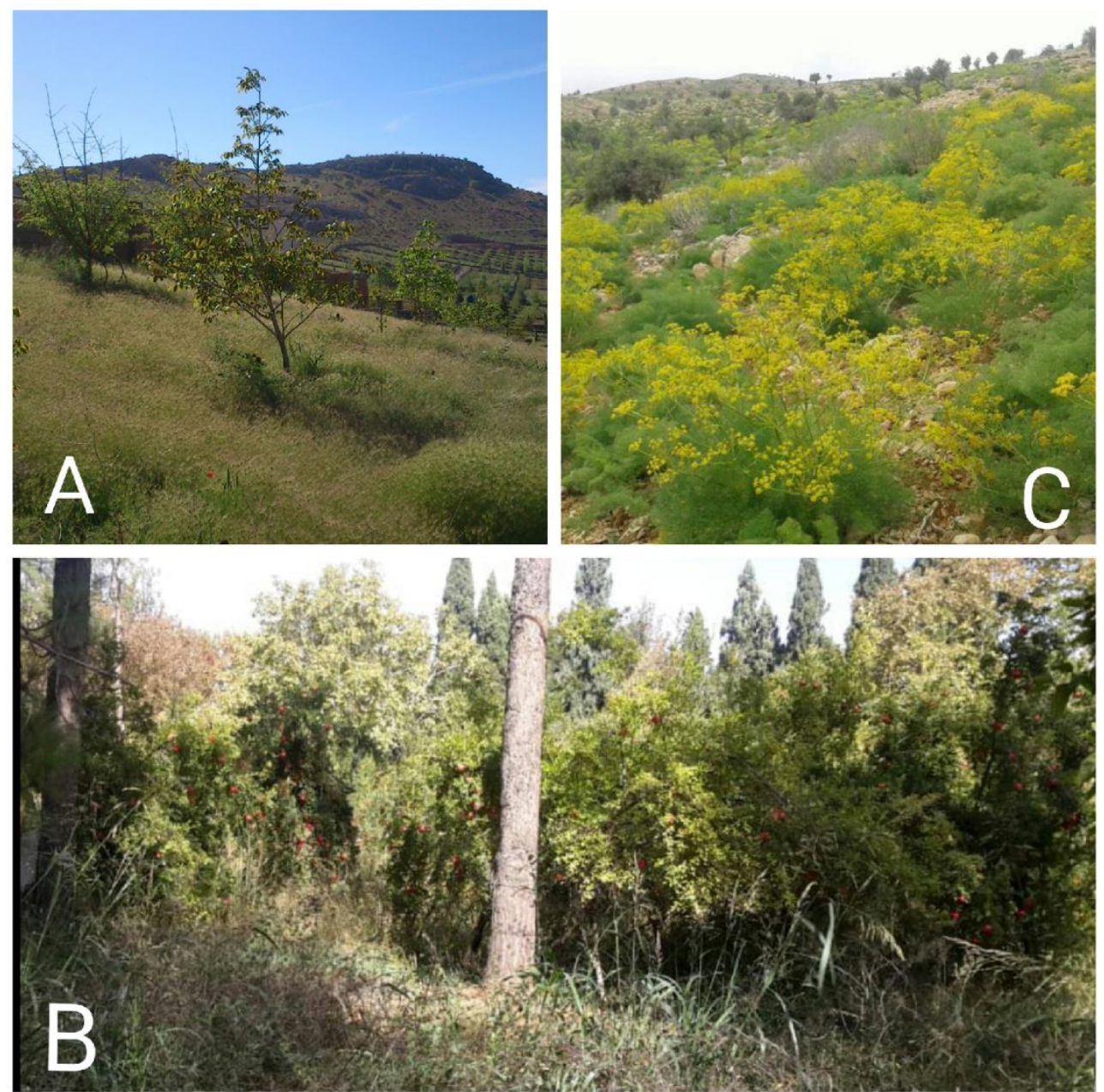

Figs. 2. Habitats of collected flies: A: Dalin, B: Shiraz, Jannat garden, C: Dasht-e Arzhan 
Loc. C): IRAN, Fars, Dasht-e Arzhan, 5159'3.439"E, 29³9'39.047"N.

Dasht-e Arzhan is a village in Arzhan rural district, Shiraz County. This village lies in an ecologically important zone that is Arzhan and Parishan protected area. The area is included into the southern Zagros, characterized by rocky ground, predominately formed by Quercus spp., together with Astragalus spp. and herbaceous plants.

Loc. D): IRAN, Fars, Larestan, 5426'1.36"E, 27³1'55.4"N.

Larestan is located in the south of Fars province and has a very hot and desert climate, with hot and dry plains, water shortages and many salt domes. The vegetation includes eucalyptus (Eucalyptus spp.), acacia (Acacia spp.), jujube (Ziziphus spp.) and olive (Olea spp.). The pastures are mostly covered with milk vetch (Astragalus spp.).

The general species distribution is given after Negrobov, Selivanova, Maslova, \& Chursina (2013) and Grichanov (2017, 2018). Type localities are provided, and country lists (in zoogeographical regions) are arranged alphabetically. Photos of some species newly recorded from Iran and habitat photos are provided. The specimens in ethanol have been studied with a ${ }^{\circledR}$ Zeiss Discovery V-12 stereomicroscope and ${ }^{\circledR}$ AxioCam MRc5 camera attachment. They will be deposited in collections of the Zoological Museum of Moscow State University, Moscow, Russia (ZMUM), the Zoological Institute of the Russian Academy of Sciences, St. Petersburg (ZIN) and the Department of Entomology, Jahrom Branch, Islamic Azad University, Jahrom, Iran.

\section{New records of Dolichopodidae Asyndetus Loew, 1869}

\section{Asyndetus albifrons Loew, 1869 (Fig. 3)}

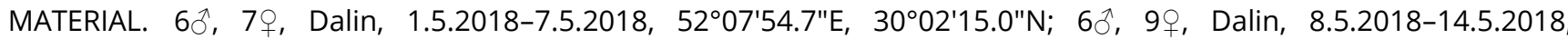

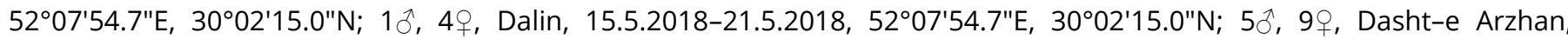

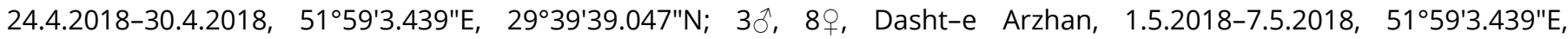

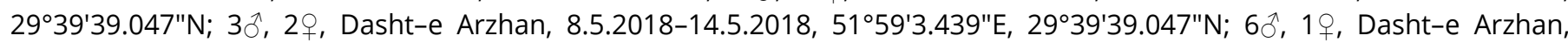

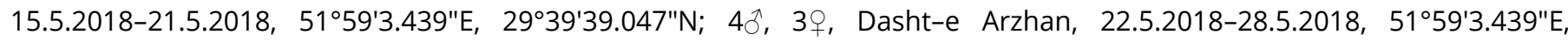

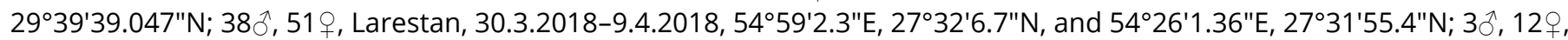

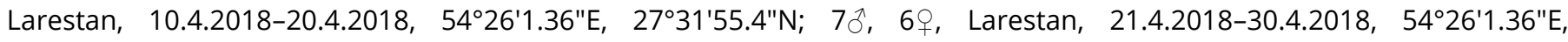

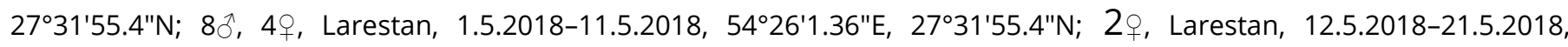

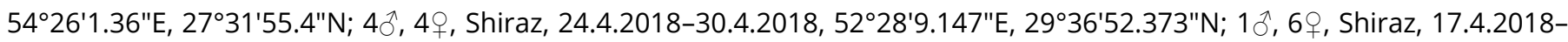

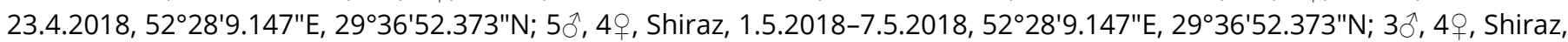
8.5.2018-14.5.2018, 52²8'9.147"E, 29³6'52.373"N.

DISTRIBUTION. Type locality: Bir Abrag (South Eastern Desert). Palaearctic or Afrotropical: Egypt (close to Hala'ib Triangle); Palaearctic: Iraq. New species for Iran.

REMARKS. The species was not appropriately illustrated and was recorded only once (from Iraq) after its description. The material examined corresponds to the original description and keys to A. albifrons in the known keys (Negrobov, 1973; Grichanov, 2007, 2013). It was the most abundant species in our samples.

\section{Asyndetus chaetifemoratus Parent, 1925 (Fig. 4)}

MATERIAL. 1 $\hat{\jmath}$, Larestan, 10.4.2018-20.4.2018, 54²6'1.36"E, 27³1'55.4"N.

DISTRIBUTION. Type locality: Egypt: Baharia Oasis. Palaearctic: Egypt, Israel, Russia (Astrakhan). New species for Iran.

REMARKS. The species was not appropriately illustrated and was recorded only two times after its description. The material examined corresponds to the original description and keys to A. chaetifemoratus in the known keys (Negrobov, 1973; Grichanov, 2007).

\section{Asyndetus sp.}

MATERIAL. 20, Dalin, 1.5.2018-7.5.2018, 5207'54.7"E, 3002'15.0"N; 2ᄋ, Dalin, 8.5.2018-14.5.2018, 5207'54.7"E,

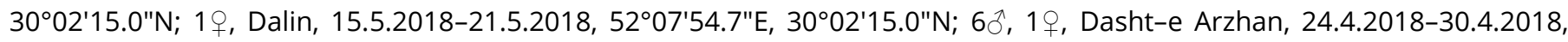

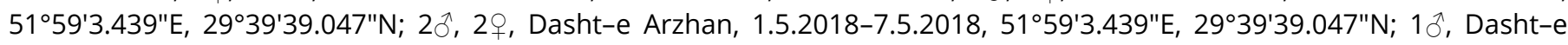

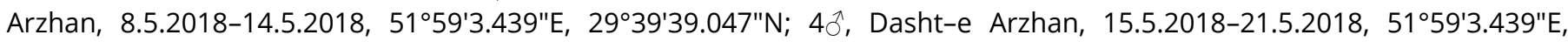

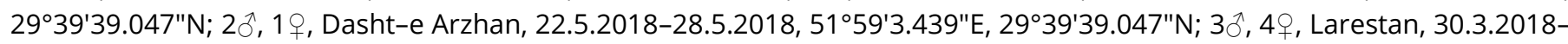

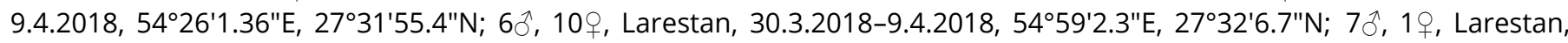

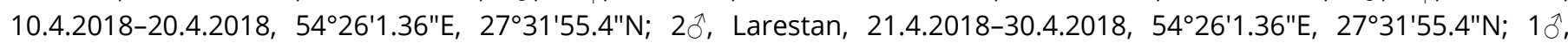

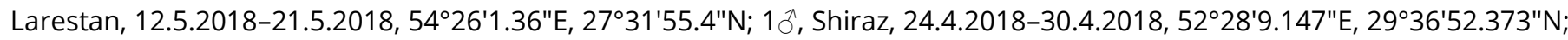

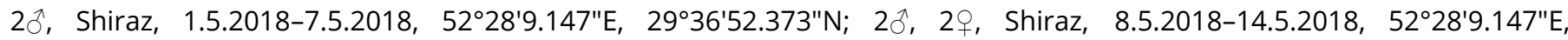
$29^{\circ} 36^{\prime} 52.373 " \mathrm{~N}$.

REMARKS. The material examined belongs most probably to an undescribed species. 


\section{Chrysotus Meigen, 1824}

REMARKS. Southern Palaearctic Chrysotus species are indistinguishable by females; therefore, 4 females collected are left unidentified.

\section{Chrysotus sp. 1}

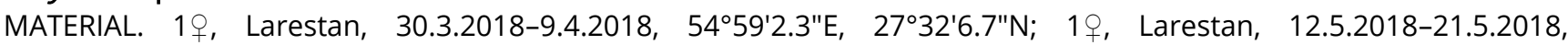
$54^{\circ} 26^{\prime} 1.36^{\prime \prime} \mathrm{E}, 27^{\circ} 31^{\prime} 55.4^{\prime \prime} \mathrm{N}$.

\section{Chrysotus sp. 2}

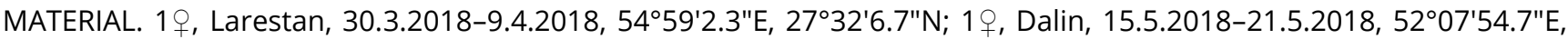
$30^{\circ} 02^{\prime} 15.0^{\prime \prime} \mathrm{N}$

\section{Medetera Fischer von Waldheim, 1819}

\section{Medetera media Parent, 1925}

MATERIAL. $1 \delta^{\lambda}$, Dalin, 8.5.2018-14.5.2018, 5207'54.7"E, 3002'15.0"N.

DISTRIBUTION. Type locality: Tunisia. Palaearctic: Egypt, Kazakhstan, Turkmenistan, Tunisia. New species for Iran.

REMARKS. This species is a sister species to Medetera flavipes Meigen, 1824, differing from the latter in yellow rather than dark fore coxa, dark at extreme apex $1^{\text {st }}-4^{\text {th }}$ segments of all tarsi and in setation of hypopygial surstylus and cercus; the tarsi are dark from apex of basitarsus in M. flavipes.

\section{Sciapus Zeller, 1842}

Sciapus adumbratus (Becker, 1902) (Fig. 5)

MATERIAL. $1 \delta^{\AA}$, Dalin, 8.5.2018-14.5.2018, 5207'54.7"E, 3002'15.0"N.

DISTRIBUTION. Type locality: [Egypt:] "Siala". Afrotropical: Oman, United Arab Emirates; Palaearctic: Egypt, Iraq, Morocco, Tunisia, Turkmenistan. New species for Iran.

\section{Tachytrechus Haliday, 1851}

Tachytrechus planitarsis Becker, 1907 (Fig. 6)

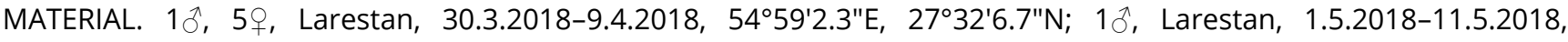
$54^{\circ} 26^{\prime} 1.36^{\prime \prime} \mathrm{E}, 27^{\circ} 31^{\prime} 55.4^{\prime \prime} \mathrm{N}$.

DISTRIBUTION. Type locality: Algeria: Biskra. Palaearctic: Algeria, Egypt, Iran, Israel, Saudi Arabia, Spain (Canary Is.), Tunisia, Turkmenistan; Afrotropical: Ethiopia.

\section{Thinophilus Wahlberg, 1844}

\section{Thinophilus sp.}

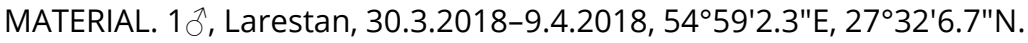

REMARKS. The material examined belongs most probably to an undescribed species. Unfortunately, the single male trapped is somewhat damaged.
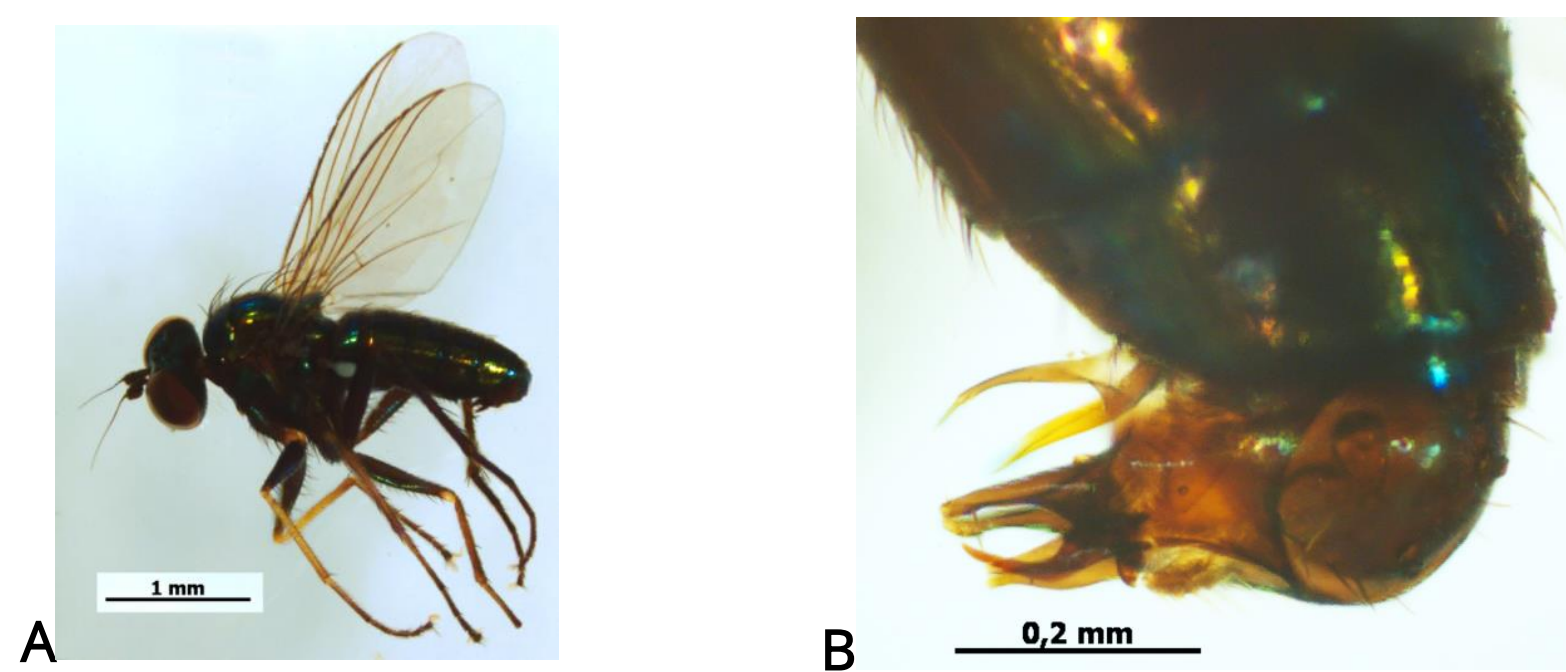

Figs. 3. Asyndetus albifrons Loew, 1869: A-male habitus; B-hypopygium. 

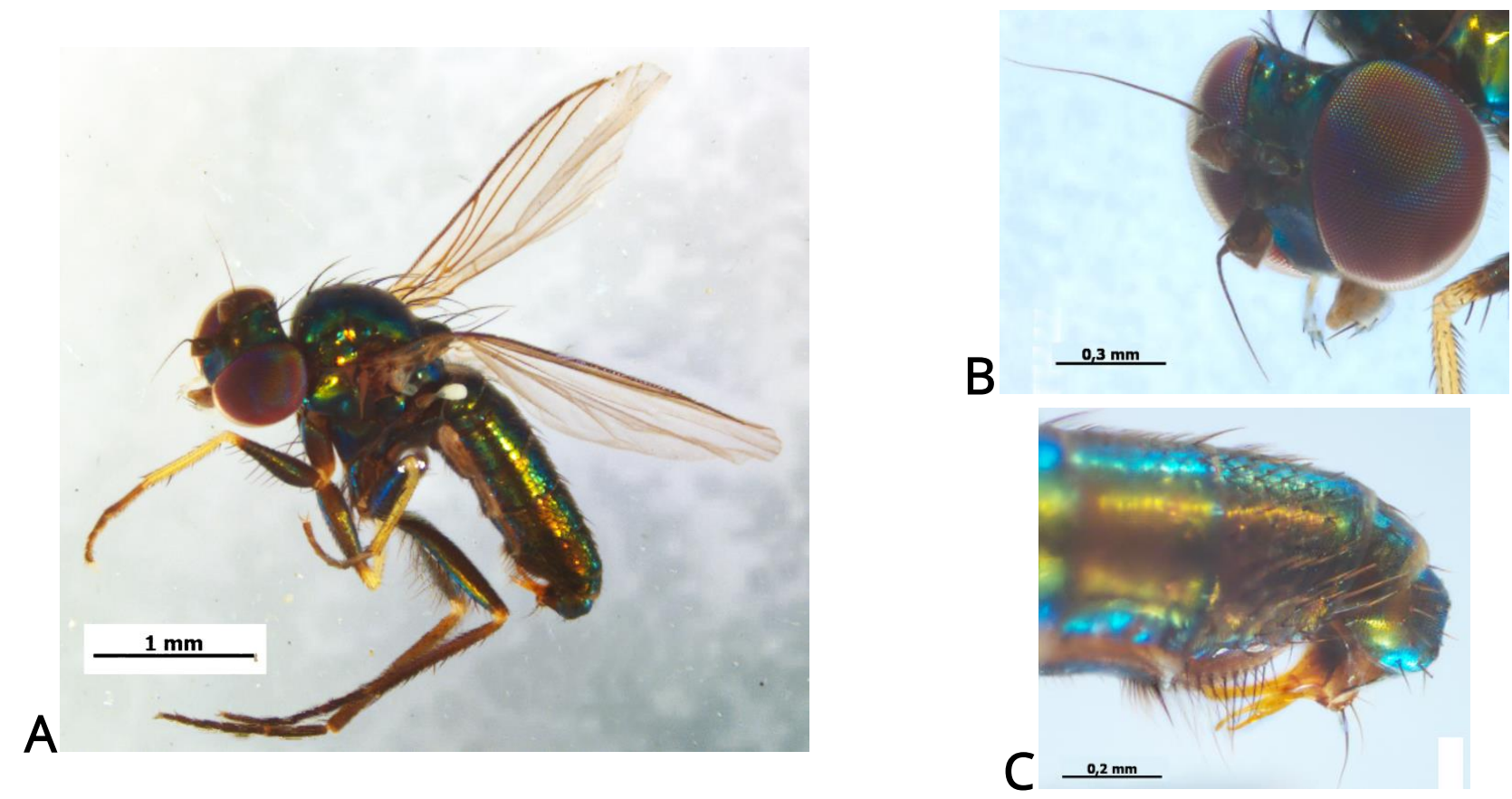

Figs. 4. Asyndetus chaetifemoratus Parent, 1925: A-male habitus; B-head; C-hypopygium.
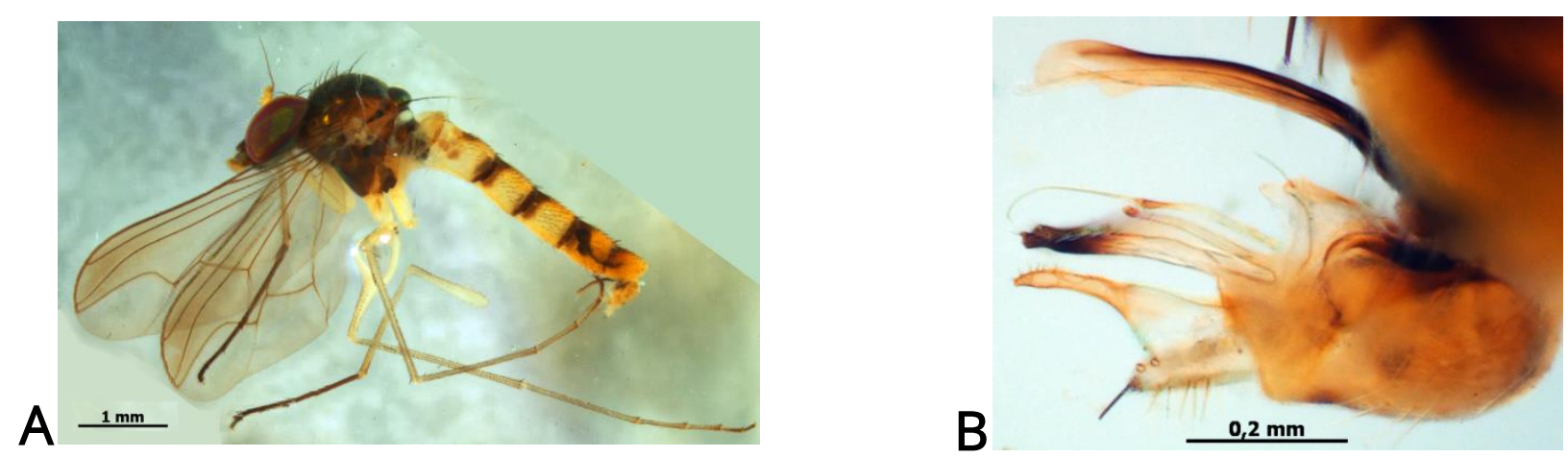

Figs. 5. Sciapus adumbratus (Becker, 1902): A-male habitus; B-hypopygium.
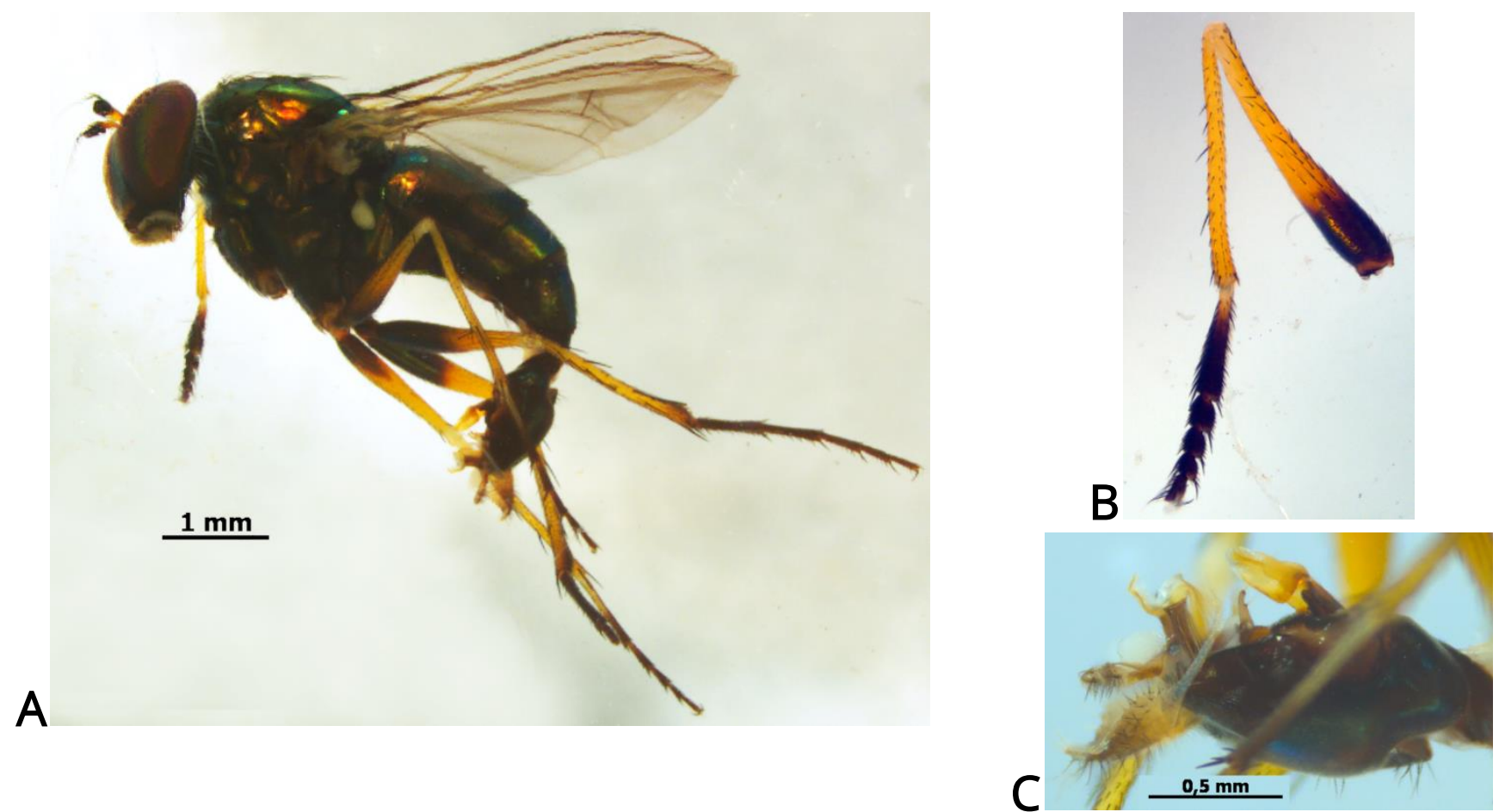

Figs. 6. Tachytrechus planitarsis Becker, 1907: A-male habitus; B-fore leg; C-hypopygium. 


\section{Discussion}

As a result of 2018 survey conducted in Fars Province, a new material of Dolichopodidae was collected and identified, belonging to 6 genera and 9 (including 4 unnamed) species listed above. The present research gives new records from the southern Iran, including Asyndetus albifrons, A. chaetifemoratus, Medetera media and Sciapus adumbratus found for the first time in Iran. In this small collection, we found two undescribed species and four species newly recorded for Iran. Such a large proportion of new species and new records indicates that the Iranian Dolichopodidae fauna is largely unknown and needs more extensive investigation. As a result of our study, the number of reported dolichopodid species from Iran includes now about 155 species. Grichanov, Ahmadi, \& Kosterin (2017) suggested that the total number of Iranian species can reach to $400-500$ species.

\section{Acknowledgements}

The research was supported by the Islamic Azad University, Jahrom Branch, Jahrom, Iran and the All-Russian Institute of Plant Protection project N 0665-2018-0002, St.Petersburg-Pushkin, Russia.

\section{References}

Ahmadi, A., Gheibi, M., Ostovan, H., Hesami, S., \& Grichanov, I.Ya. (2016). New records of Dolichopodidae (Diptera) from Central Provinces of Iran. Halteres, 7, 191-196. Available from: http://www.antdiversityindia.com (accessed 15 October 2018).

Ahmadi, A., Gheibi, M., Ostovan, H., Hesami, S., \& Grichanov, I.Ya. (2017). New records of long-legged flies (Diptera, Dolichopodidae) of Iran. Russian Entomological Journal, 26(1), 65-70. Available from: http://kmkjournals.com/upload/PDF/REJ/26/ent26 1065070 Ahmadi et al for Inet.pdf (accessed 15 October 2018).

Grichanov, I.Ya. (2007). A checklist and keys to Dolichopodidae (Diptera) of the Caucasus and East Mediterranean. St.Petersburg: VIZR, 1-160 (Plant Protection News Supplements). Available from: http://www.diptera.info/downloads/Grichanov 2007b.pdf (accessed October 2018).

Grichanov, I.Ya. (2013). Afrotropical species of the genus Asyndetus Loew (Diptera: Dolichopodidae) with notes on some Palaearctic and Oriental species. In: Grichanov, I.Ya., Negrobov, O.P. (Eds.). Fauna and taxonomy of Dolichopodidae (Diptera). Collection of papers. St.Petersburg: VIZR RAAS (Plant Protection News Suppl.), 27-46. Available from: https://archive.org/details/GrichanovNegrobovDolichopodidae2013 (accessed October 2018).

Grichanov, I.Ya. (2017). Alphabetic list of generic and specific names of predatory flies of the epifamily Dolichopodoidae (Diptera). 2nd Edition. St.Petersburg: VIZR, 1-563. (Plant Protection News Supplements, N23). Available from: https://archive.org/download/Grichanov2017DolibankSec/Grichanov\%202017\%20Dolibank-sec.pdf (accessed 15 October 2018).

Grichanov, I.Ya. (2018). An annotated catalogue of Afrotropical Dolichopodoidae (Diptera). St.Petersburg: VIZR, 1-152. (Plant Protection News, Supplements, N25). Available from: http://doi.org/10.5281/zenodo.1187006 (accessed 15 October 2018).

Grichanov, I.Ya., Ahmadi, A., \& Kosterin, O.E. (2017). New records of long-legged flies (Diptera, Dolichopodidae) from Central and North-Eastern Iran. Acta Biologica Sibirica, 3(4), 99-112. DOI: https://doi.org/10.14258/abs.v3i4.3636

Kazerani, F., Khaghaninia, S., \& Grichanov, I.Ya. (2014). The genus Dolichopus Latreille diversity in three different habitats of East Azerbaijan province, with new records for Iran. Arxius de Miscellània Zoològica, 2013, 11, 134-152. Available from: http://amz.museucienciesjournals.cat/files/AMZ_vol 11_2013 pp_134-152_Kazerani et al.pdf (accessed 15 October 2018).

Kazerani, F., Khaghaninia, S., Talebi, A.A., Persson, M., \& Pollet, M. (2017). Eight new species of Dolichopodinae (Diptera: Dolichopodidae) from northern Iran. Zootaxa, 4242(1), 111-141. DOI: https://doi.org/10.11646/zootaxa.4242.1.6

Khaghaninia, S., Gharajedaghi, Y., \& Grichanov, I.Ya. (2014). A contribution to the knowledge of the family Dolichopodidae (Diptera) in East Azerbaijan province of Iran. Check List: The Journal of Biodiversity Data, 10(3), 588-593. DOI: http://dx.doi.org/10.15560/10.3.588.

Negrobov, O.P. (1973). Zur Kenntnis einiger palaearktischer Arten der Gattung Asyndetus Loew. Beiträge zur Entomologie, 23, 157-167.

Negrobov, O.P., Selivanova, O.V., Maslova, O.O., \& Chursina, M.A. (2013). Check-list of predatory flies of the family Dolichopodidae (Diptera) in the fauna of Russia. In: Grichanov, I.Ya., Negrobov, O.P. (Eds.). Fauna and taxonomy of Dolichopodidae (Diptera). Collection of papers. St.Petersburg: VIZR RAAS (Plant Protection News Suppl.), 47-93. Available from: https://archive.org/details/GrichanovNegrobovDolichopodidae2013 (accessed 15 October 2018).

\section{Citation:}

Rezaei, S., Grichanov, I.Ya., \& Fallahzadeh, M. (2019). First records of long-legged flies (Diptera, Dolichopodidae) from Fars Province of Iran. Acta Biologica Sibirica, 5 (1), 6-11.

Submitted: 23.11.2018. Accepted: 05.01.2019

cross ref http://dx.doi.org/10.14258/abs.v5.i1.5184

(C) 2018 by the authors. Submitted for possible open access publication under the terms and conditions of the Creative Commons Attribution (CC BY) license (http://creativecommons.org/licenses/by/4.0/). 